\title{
The painful search of a painless labour
}

During the 12th and 13th centuries, rivalry between "The Guelphs" and "The Ghibellines" (factions supporting the Church and the Holy Roman Empire, respectively) characterized a particularly intense aspect of the internal politics in the city-states of central and northern Italy, particularly in Tuscany. The GuelphGhibelline conflict, which was described also in Dante's Divina Comedia, gave way to an especially ferocious and painful civil war lasted for decades, and ending without a real winner [1].

In 2000, a preliminary investigation on remifentanil as a systemic drug for obstetric analgesia concluded that remifentanil was "unsuitable during labour" [2]. Months later (2001) a prospective study on the same topic stated that it had the properties of an "ideal systemic analgesic for use during labour" [3]. Since then something like 160 articles evaluating the use of intravenous remifentanil for labour analgesia, resulted in mixed findings regarding its safety and efficacy in attenuating labour pain if compared with other opioids or neuraxial techniques. Some strong statements were in favor of remifentanil “... it is an important advance in the obstetric anesthesia armamentarium for parturients who do not want neuraxial analgesia" [4]. While some others were against it: “... routine use in labour must be discouraged ... must we press on until a young mother dies?" [5]. This scientific epistolary conflict (no holds barred) sounds like the "Guelphs vs Ghibellines" but among two obstetric anesthesiologists "factions", and it has been now lasting for two decades: on one hand those who strongly supported the technique and on the other, with just as much commitment, the opponents.

The pain associated with labour is highly personal and varies greatly among individual, but most of women do experience anything but modest pain during labour, resulting in negative physical, emotional and psychological effects [6].

In the December issue of Trends in Anaesthesia and Critical Care [7], Andrea Melber and Alex Sia, explore efficacy, safety and risks of remifentanil Patient-Controlled intravenous Analgesia (PCA) for labour in relation to the other better established pharmacological methods. We want to thank the authors to point out some worthy-of-support statements and to provide us with the opportunity to make a point.

Firstly: "the efficacy of remifentanil PCA may be found between neuraxial analgesia and other commonly used pharmacological techniques." Based on current evidence remifentanil PCA provides better analgesic quality than pethidine and nitrous oxide, the two "pharmacological competitors". However, remifentanil remains significantly less effective when compared to neuraxial analgesia. Remifentanil appears more effective during the first stage compared to the second stage of labour, when somatic pain, more resistant to opioids, occurs. Furthermore tachyphylaxis, remifentanil-induced hyperalgesia, or difficulty to synchronize the peak of remifentanil effect with the peaks of contractions might further explain its reduced efficacy [8,9].

Secondly: “... the serious concern for maternal safety is justified. Thorough and continuous observation during the application of remifentanil PCA is of utmost importance." The fast onset of action and rapid clearance are properties that should make remifentanil an ideal drug for PCA use, but its potency may cause serious side effects [10]. Literature reported cases of remifentanil PCA associated with nausea and vomiting, arterial hypotension, muscle stiffness, bradycardia, hyperalgesia but especially respiratory depression (up to 26\% of treated patients) [11]. Case reports of more serious events, such as cardiac arrest (presumably arising from induced respiratory arrest) have been described [12].

The variations in the bolus dose required for effective analgesia (20-60 mcg, 1-3 min of lockout) and the difficulties in identifying the optimal administration of remifentanil during labour (PCA, continuous infusion or a combination of PCA and a continuous infusion) may have a different impact on patient safety [13]. Oxygen supplementation and continuous monitoring of vital signs (blood pressure, heart rate, respiratory rate, $\mathrm{SpO}_{2}, \mathrm{EtCO}_{2}$, level of consciousness) must be ensured. One-to-one midwifery/nursing care, the availability of a physician experienced in neonatal resuscitation and a supervising anesthesiologist, with experience regarding the use of remifentanil, are important to ensure that this method retains its credit for obstetric analgesia. Unrealistic expectations in terms of analgesia by patients and staff increase the risk for an adverse event [14].

From the fetal-neonatal side, remifentanil has less side effects than other parenteral opioids. Should reduced fetal heart rate variability be observed, the reported need for neonatal resuscitation is low [8].

Thirdly: "In the use of Remifentanil PCA ... new technology ... will hopefully improve this aspect of care for the parturient". In addition to one-to-one midwifery/nursing surveillance, with the aim of increasing the safety of remifentanil analgesia, a promising novel feedback system, integrating a vital signs-controlled and patientassisted intravenous remifentanil analgesia (VPIA) has been developed [15]. The system automatically increases or decreases the bolus doses based on parturient's requests of remifentanil and stops further remifentanil administration in the presence of maternal hypoxia, thanks to integrated real-time continuous maternal data obtained from pulse oximetry and heart rate values. An implementation of the system with capnography and fetal heart rate monitoring has been recommended [16]. An algorithm based on a time series of painful contractions during labour, which can predict the future contractions with sufficient precision, optimizing remifentanil bolus application and so improving the efficacy of PCA during first-stage labour, has also been developed [17].

Two final considerations. Remifentanil PCA technique will become safer and more effective than it is today, however a strong 
reason for supporting epidural labour analgesia is the ability to rapidly convert analgesia to surgical anesthesia for unscheduled cesarean delivery. Especially in complicated parturients (e.g. morbidly obese) the early placement of an epidural catheter for labour analgesia can avoid the associated risks of general anesthesia when operative delivery/non scheduled cesarean section is required [18]. Based on current scientific evidence, neuraxial analgesia seems to be the only "routine" viable option and probably the actual gold standard for labour analgesia, which someway results in a painful search of a painless labour.

Women requesting pain relief for labour who have contraindications for an epidural block (impaired coagulation due to prophylactic anticoagulants, or pre-existing blood clotting abnormality or platelet dysfunction) or when central neuraxial analgesia may be technically impossible to perform, could benefit from intravenous remifentanil analgesia. However significant availability of medical staff and monitoring devices, and large-scale studies are needed before remifentanil can be safely recommended as a "standard" in this context.

Until this time comes, our duty is to pursue patients' safety and satisfaction, and to provide, as from excellent research from Melber and Coworkers [7], the search of the perfect painless labour. A search which is part of our nature, as from same Dante Alighieri's words:

"Considerate la vostra semenza: fatti non foste a viver come bruti, ma per seguir virtute e conoscenza" ["Consider ye the seed from which ye sprang: Ye were not made to live like unto brutes, But for pursuit of virtue and of knowledge"] [19].

\section{References}

[1] S. Raveggi, L'Italia dei Guelfi e Ghibellini, Bruno Mondadori, 2009.

[2] A.J. Olufolabi, J.V. Booth, H.G. Wakeling, et al., A preliminary investigation of remifentanil as a labor analgesic, Anesth. Analg. 91 (2000) 606-608.

[3] J.M. Blair, D.A. Hill, J.P. Fee, Patient-controlled analgesia for labour using remifentanil: a feasibility study.Br J Anaesth 87 (3) (2001 Sep) 415-420.

[4] A. Hinova, R. Fernando, Systemic remifentanil for labor analgesia, Anesth Analg. 109 (2009) 1925-1929.

[5] P. Kranke, T. Girard, P. Lavand'homme, et al., Must we press on until a young mother dies? Remifentanil patient controlled analgesia in labour may not be suited as a "poor man's epidural, BMC Pregnancy Childbirth 13 (2013 Jul 2) 139.

[6] R. Melzack, The myth of painless childbirth, Pain 19 (1984) 321-337.

[7] A. Melber, A. Sia, "Do no harm" - where to place remifentanil for labour analgesia? Trends in Anaesthesia and Critical Care 17 (2017) 17-20.

[8] M. Van de Velde, B. Carvalho, Remifentanil for labor analgesia: an evidencebased narrative review, Int. J. Obstet. Anesth. 25 (2016) 66-74.

[9] S. Labor, S. Maguire, The pain of labour, Rev Pain 2 (2) (2008) 15-19.

[10] S. Evron, M. Glezerman, O. Sadan, et al., Remifentanil: a novel systemic analgesic for labor pain, Anesth. Analg. 100 (2005) 233-238.

[11] D. Stocki, I. Matot, S. Einav, et al., A randomized controlled trial of the efficacy and respiratory effects of patient-controlled intravenous remifentanil analgesia and patient controlled epidural analgesia in labouring women, Anesth. Analg. 118 (2014) 589-597.

[12] R. Marr, J. Hyams, V. Bythell, Cardiac arrest in an obstetric patient using remifentanil patient-controlled analgesia, Anaesthesia 68 (3) (2013) 283-287.

[13] P. Volmanen, E. Akural, T. Raudaskoski, S. Alahuhta, Remifentanil in obstetric analgesia: a dose finding study, Anesth. Analg. 94 (2002) 771-773.

[14] B. Anderson, The use of remifentanil as the primary agent for analgesia in parturients, Crit. Care Nurs. Clin. 29 (2017) 495-517.

[15] W.L. Leong, B.L. Sng, Q. Zhang, R. Han LNR,Sultana, A.T. Sia, A case series of vital signs-controlled, patient-assisted intravenous analgesia (VPIA) using remifentanil for labour and delivery, Anaesthesia 72 (2017) 845-852.

[16] C.F. Weiniger, B. Carvalho, R. Landau-Cahana, Optimising triggers for patient assisted remifentanil analgesia during labour, Anaesthesia 72 (2017) 1155.

[17] B. Rehberg, N. Wickboldt, C. Juillet, G. Savoldelli, Can remifentanil use in obstetrics be improved by optimal patient-controlled analgesia bolus timing? Br. J. Anaesth. 114 (2) (2015) 281-289.

[18] F. Petrini, I. Di Giacinto, R. Cataldo, et al., Obesity task force for the SIAARTI airway management study group. Perioperative and periprocedural airway management and respiratory safety for the obese patient: 2016 SIAARTI consensus, Minerva Anestesiol. 82 (2016) 1314-1335.

[19] Dante Alighieri, The Divine Comedy: Inferno, Canto XXVI, Vv 118-120. Ed. And Trans. Mark Musa, Indiana UP, Bloomington, 1995.

Massimo Micaglio ${ }^{a, *}$, Massimiliano Sorbello ${ }^{\mathrm{b}}$, Alessandro Di Filippo $^{\mathrm{a}}$

a Department of Anesthesia and Intensive Care, Azienda OspedalieroUniversitaria Careggi Florence, Italy

${ }^{\mathrm{b}}$ Department of Anesthesia and Intensive Care, Policlinico Vittorio Emanuele University Hospital, Catania, Italy

* Corresponding author. E-mail address: micagliom@aou-careggi.toscana.it (M. Micaglio). 